Ročník XVIII (2016), Číslo 1, s. 110-114/ Volume XVIII (2016), Issue 1, pp. 110-114

(c) Mezinárodní politologický ústav / International Institute of Political Science

DOI: $10.5817 / C E P S R .2016 .1 .110$

\title{
Alina Bârgăoanu, Loredana Radu and Diego Varela (eds.): United By or Against Euroscepticism? An Assessment of Public Attitudes towards Europe in the Context of the Crisis
}

\author{
UK: Cambridge Scholars Publishing, 2015, 248 pp., ISBN 978-1-4438-8090-9
}

\section{DANA RALUCA BUTUROIU ${ }^{1}$}

This edited volume is a detailed analysis of public attitudes towards the European Union. Specifically, the book offers a multi-layered perspective (i.e., based on political science, sociology, communication and media studies) on the main processes that lie behind the emergence and development of public attitudes towards the EU. The book encompasses empirical approaches based on quite solid theoretical grounds to the rise of Eurosceptic attitudes in countries both inside and outside the EU. All of them tend to have a common aim. Specifically, they seek to offer a big picture embedding the main reasons behind and the possible consequences of critical, sceptic or downright anti-European attitudes. The book has appeared in the perfect empirical setting - the EU is struggling with a series of crises and its citizens are asking for EU-rooted solutions. Thus, the book reveals that the focus of research has shifted from simply ascertaining the difficulties which the EU has to face to understanding people's needs with respect to expressing their feelings and attitudes towards more or less new European crises.

The book includes ten chapters grouped in four sections. The first section consists of two cross-national studies assessing attitudes towards the European Union in times of crisis. The first chapter in this section starts from the utilitarian theory, which states that "EU citizens in different socioeconomic situations experience different costs and benefits from integrative policy and these differences in economic welfare shape their attitudes toward integration" (p. 20). Within this theoretical framework, the author discusses the relationship between the high number of crises that the EU has to face and its citizens' (less enthusiastic) attitudes towards the EU. The main stated objective of this chapter is

${ }^{1}$ College of Communication and Public Relations, National University of Political Studies and Public Administration, Bucharest, Romania. Contact: raluca.buturoiu@comunicare.ro. 
to assess the most recent attitudes towards the EU (i.e., Eurosceptic attitudes), with a special emphasis on possible differences inside the EU (between the perceptions of citizens from the old and new Member States, as well as between the attitudes of citizens from the southern and northern Member States). The conclusions suggest that the rise in Eurosceptic attitudes follows a utilitarian perspective: the lower the economic benefits that citizens perceive as a consequence of being part of the European Union, the greater their desperation and mistrust in the EU. The second chapter in this section focuses on the idea that there are at least five main explanatory theories which are used to explain support for the EU, namely cognitive mobilization, post-materialism, utilitarianism, the theory of "proxies", and nationalism (p. 47). One main conclusion of the chapter is that, mainly in the context of multiple crises, utilitarian factors play a vital role in changing attitudes towards the EU.

The second section consists of two chapters that are quite divergent from a theoretical perspective, but similar in some methodological aspects because they are based on qualitative methods, namely interviews. One of the chapters assesses public attitudes towards the EU using a comparative approach (in Spain versus the UK). It follows the controversial political theories advanced by Carl Schmitt, whose main theoretical assumptions relate to the idea that "the twin deficit of weak domestication and technocratic depoliticisation predates the recent crisis" (p. 66). The main findings show that "Spaniards have become even more mistrustful of the EU than the British", meaning that there is a flimsy line between extreme and moderate attitudes towards the EU and that even pro-European countries need to find solutions to avoid the generalization of negative attitudes towards the EU. In contrast, the second chapter focuses on the communication dimension, mainly derived from identity-based processes. In this sense, the main emphasized theoretical idea is that there is a lack of communication on the European level that causes unwanted (i.e., negative) attitudes. In other words, anti-EU attitudes emanate from the inconsistent development of a European public sphere. This is why one main suggestion for reducing the impact of Eurosceptic attitudes is the use of formal channels of communication, since it "could play a role in the change of orientation but only when it follows certain rules and is well coordinated" (p. 110).

The third section comprises four contributions towards understanding EU-related public attitudes in Eastern Europe, namely in Romania, Slovenia, Turkey and Ukraine. The first chapter in this section consists of a qualitative analysis (using interviews) of young Romanian's perceptions of the EU based on three dimensions - the identity-based dimension, the political dimension, and the utilitarian dimension. Using a secondary Euro barometer analysis, the second chapter assesses the impact of instrumental factors (i.e., the benefits flowing from, and the problems caused by the EU) on the feeling of identification with European social spaces; the empirical analysis is conducted with reference to 
Slovenes. The third chapter consists of both qualitative and quantitative content analyses of news articles covering the Eurozone crisis during peak events in Turkey (i.e., the election period in 2011). The fourth chapter in this section has two main declared objectives - one of them is to reveal the character of trust (i.e., political or non-political) towards "European values in the civil disobedience during the Euromaidan ${ }^{2}$ protests" (p. 189), while the other is to reveal the main myths built and nurtured around European values in Ukraine, by using two theoretical approaches (the approach of Hobbes on the state social contract and that of Spinoza on democracy).

The main findings of the third section show that Romanian young people tend to describe themselves as mildly Eurosceptic, but mainly with reference to less favourable EU-related contexts (i.e., the economic crisis). Moreover, the findings confirm that not only Romanians, but also other people from the European Union (i.e., Slovenes) tend to perceive their affiliation to Europe in instrumental terms (i.e., in terms of costs and benefits). In some countries (e.g., Romania and Slovenia), the lack of perceived advantages coming from EU membership could be the main cause of Euroscepticism. However, the situation in Turkey seems to function the other way round - neither the low coverage of EU-related topics in the national media (i.e., the insufficient development of a European public sphere), nor the local political discourse can be made responsible for fostering anti-European attitudes. In contrast, the context in Ukraine seems to give rise to extremely polarised attitudes between proEuropeans and pro-Russians.

The fourth section explores EU-related attitudes in connection to the future of the European Union. The first chapter in this section is based on the idea that one major cause of Euroscepticism is the lack of a bird's-eye view encompassing global challenges. Specifically, the author suggests that there are some discursively-related issues that might be more easily and efficiently solved at the EU-level than by individual states. To put it differently, this contribution suggests that there is a need to become publicly aware of global challenges if each Member State society aims at "turning [...] into a European society" (p. 219). This statement offers grounds for concluding that Euroscepticism might be regarded more as a European public sphere facilitator than as a factor limiting the elevation of the European project. In contrast, the second chapter of this section is dedicated to the idea that "the current Euroscepticism is rather benign" (p. 224), meaning that it has become a generalized phenomenon, being present all across the European Union. Nevertheless, there is the so-called "new Euroscepticism"

\footnotetext{
2 As explained in the book, “The word 'maidan' (Persian 'meydan', Ukrainian 'майдан') refers to any open place or a public square" (p. 190). Following this definition, Euromaidan protests are movements organized in public places or squares (also called Maidans) in order to claim different things relating to the EU (rights, protection, support, etc.).
} 
(p. 241), coming from the much delayed responses of the EU to citizens' questions (especially on economic topics), which is an issue that should be addressed in more detail by researchers.

All these sections contribute equally to a better understanding of the main (negative) public attitudes towards the EU and are based on theoretical grounds in the areas of political studies, sociology, as well as communication and media studies. Within these areas, this book is not unique; other volumes on similar topics are also available. Nevertheless, the main strengths of the book reside in at least two directions. The first is related to its original argument for coming into existence - the need to unveil public positions towards the European Union in a context marked by profound crises and the preoccupation with studying these perceptions with an eye to the future of the EU - that is, whether and how these anti-European views could impact on the European project (either as positive or negative drivers). The second relates to the diverse, but connected types of contribution. While the first section offers a more general view on Euroscepticism, the second one focuses on analysing Eurosceptic attitudes in times of crisis, the third one comprises a detailed analysis of attitudes towards the EU in countries such as Romania, Slovenia, Turkey and Ukraine (countries with quite different characteristics, in the sense that Romania is quite a new member of the EU, while Turkey and Ukraine are countries in which EU membership is highly debated), and the fourth one unveils the implications of negative attitudes towards the EU.

The book could represent a useful tool for both experts and non-experts. For the expert eye, this volume could facilitate the emergence of new research directions in the study of EU-related perceptions. For example, due to their diverse provenance and the methodologies used to acquire them, some findings could be used as starting points for future research studies on public attitudes towards Europe. On the other hand, for non-experts, the book could serve as a bildungsroman. Specifically, general readers might find the book to be an initiation into the process of coming closer to EU-rooted public attitudes. They might understand why and how EU citizens tend to develop mainly negative attitudes in times of crisis.

The book functions as a confirmation of the fact that there is an increasing need to understand the causes and effects of European crises from the citizen's perspective. The common ground of all the contributions from the volume refers to negative EU-related attitudes, namely Euroscepticism. Thus, as the title evokes, we notice that there is a permanent conflict in the EU-level arena - Eurosceptic attitudes function as a motivator both for and against the EU project. While some people feel more optimistic about working together in order to find common solutions to problems, others lose their optimism and develop a sense of powerlessness, which, in turn, causes doubt with reference to the capacity and strength of the European Union. 
One major contribution of this book is the diversity and well-documented nature of its viewpoints. Coming from their theoretical backgrounds, and through their multiple, yet connected areas of interpretation, the contributions from the volume form a detailed approach to public attitudes towards the European Union in the context of multiple crises. Nevertheless, there are two points of criticism. First, the contributors tend to use a rather deductive approach in their research. Explicitly, they start from the idea that, in times of multiple crises, there is a high possibility that extremely negative EU-related attitudes should come to light at the citizens' level. Guided by the idea that Eurosceptic attitudes are increasing in the context of numerous crises that affect Europe, their interpretations might be biased in the sense that while some European citizens seem to struggle against Euroscepticism, others are more united just because they share the same Eurosceptic feeling. Thus, the researchers should have paid attention to this particular aspect when formulating their conclusions. Second, due to their different research methodologies and theoretical approaches, the general conclusions and recommendations are rather divergent and could be confusing for the general reader. While some authors conclude that Euroscepticism is certainly on the rise, others opt for more moderate visions. These quite contentious positions contribute to understanding the enigmatic nature of the ways in which citizens perceive the European Union. Moreover, the puzzling effect is even greater when taking into account the fact that, sooner or later, citizens' perceptions could be transformed into behaviour. This context induces certain questions to be asked. For example, will citizens' actions correspond to their perceptions? Do the Eurosceptic attitudes towards the EU entail Eurosceptic action, or is another scenario possible? Might Eurosceptic perceptions function as a driving force behind a more positive stance towards the EU? Nevertheless, these points do not disturb the persuasiveness or complexity of this volume, which brings a fresh perspective on how we (should) understand public attitudes towards Europe in hard times. 